\title{
Arte urbano, ¿patrimonio cultural etnográfico de nosotros mismos?
}

Mercedes Sánchez Pons | Dpto. de Conservación y Restauración, Universitat Politécnica de Valencia

URL de la contribución <www.iaph.es/revistaph/index.php/revistaph/article/view/4926>

Por su etimología, vinculamos el término patrimonio cultural a la herencia del pasado, a aquellos elementos que existían con anterioridad a nosotros, que hemos recibido y consideramos que definen nuestra historia colectiva como sociedad, y que, por tanto, sentimos el deber de preservar para que también las futuras generaciones puedan conocerlo.

Con el arte urbano, nos encontramos ante patrimonio de nueva factura, no heredado, en proceso de construcción. Un ámbito de producción cambiante, heterogéneo, al que en ocasiones se le asigna, por determinadas circunstancias, valores dispares (Brajer 2015), pudiendo llegar a adquirir, alguna obra en particular, diferentes niveles de protección, atribuidos a veces de un modo discrecional.

El interés que este tipo de obras genera es indudable y crece de forma exponencial, tanto desde el punto de vista social -y como consecuencia, económico- como académico.

En los últimos años la aceptación social del street art y el intento de separarlo, por parte de las instituciones, del acto ilegal, como sucede en la ciudad de Melbourne ${ }^{1}$, ha llevado a situaciones que han contribuido a la transformación del fenómeno en sí mismo y a su natural evolución, coexistiendo diferentes formas y modos de vivirlo por quienes lo practican y también por quienes conviven con él o son responsables de los espacios en los que se realiza. Numerosos centros históricos de ciudades, declarados BIC, como puede ser el caso de Valencia, o incluso Patrimonio de la Humanidad, por UNESCO, como George Town o Valparaíso, están repletos de manifestaciones ilegales, autorizadas y comisionadas, convirtiéndose incluso en un aliciente para el turismo, la generación de identidad y la agitación cultural, aprovechado tanto por iniciativas privadas como institucionales.

Asimismo, se han disparado los trabajos académicos e investigaciones del estudio del marco conceptual y teórico de su producción, desde diversos prismas de análisis (urbanístico, antropológico, sociocultural), así como de aquellas relativas al conocimiento de los materiales que integran las obras y sus mecanismos de deterioro, como las desarrolladas por el grupo de Arte Urbano y Público del Ge-IIC ${ }^{2}$ o el reciente Proyecto $\mathrm{CAPUS}^{3}$, financiado por la Unión Europeo en el marco del programa ERASMUS+.

El concepto de patrimonio cultural está ligado ineludiblemente a las convenciones legales derivadas de ese reconocimiento, adaptadas al sistema legislativo de cada nación o región con competencias, con la asignación inmediata de un nivel específico de protección y de unas obligaciones para con el bien y sus custodios. Atendiendo a la definición de patrimonio cultural que ofrece UNESCO y a los trabajos previos que han explorado esta idea en ocasiones anteriores (Nogueira 2014; Merrill 2015; Luque y Moral 2021), no parece que tenga sentido plantear como patrimonio cultural el conjunto de un fenómeno tan heterogéneo y cambiante como el que recoge la etiqueta "arte urbano", término que además tiene diferentes lecturas según el contexto en el que se utiliza.

Fuera de cuestionamiento está, sin embargo, el hecho de que una determinada obra, entendida bajo el término de "arte urbano", ya sea ilegal, autorizada o comisionada, pueda ser reconocida como patrimonio cultural, obteniendo por tanto un nivel de protección oficial, puesto que esto ya ha sucedido y en lugares tan dispares como 


\section{Cand}
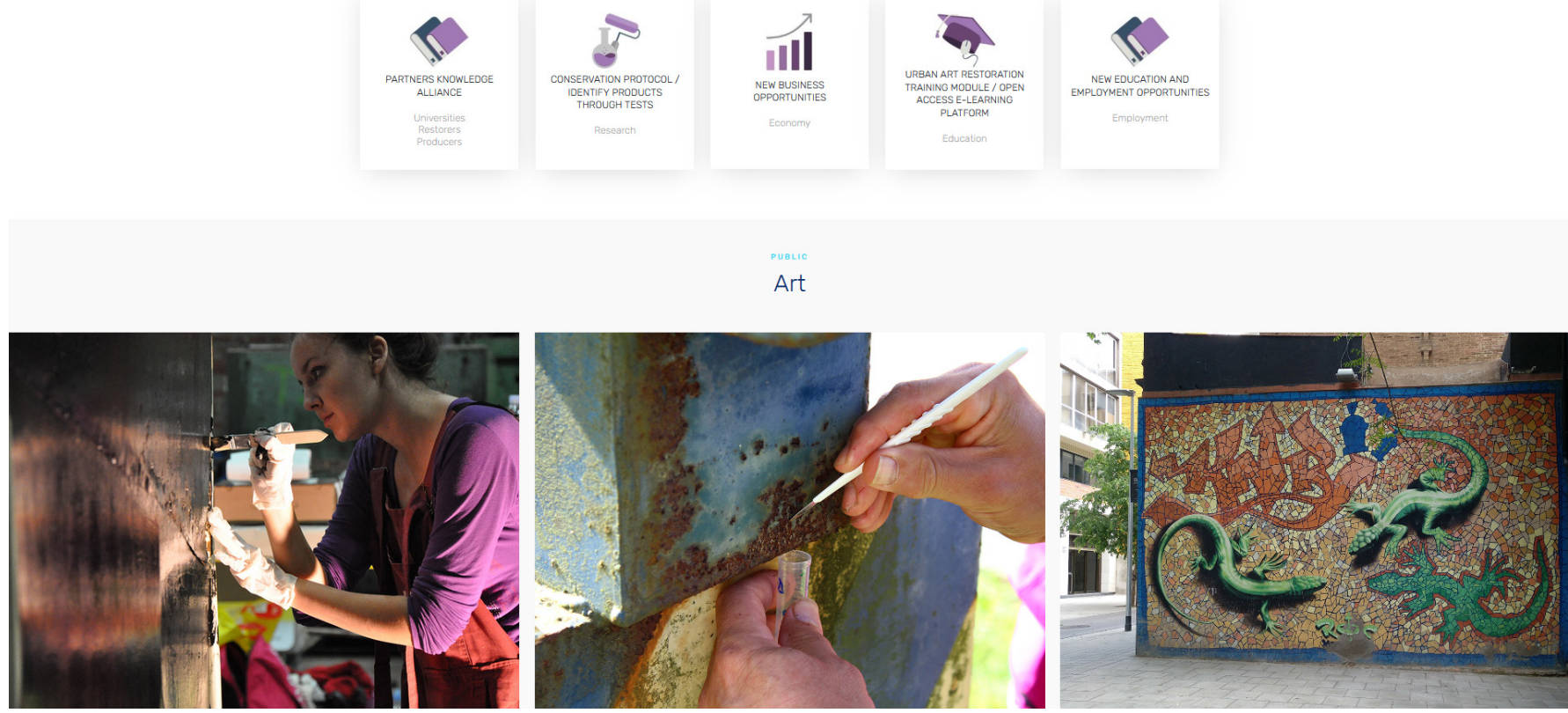

http://www.capusproject.eu/

puede ser Granada, con el mural Jesús Arias, realizado por EI Niño de las Pinturas y declarado BIC por la Junta de Andalucía en 2017; en Melbourne, con el mural de Keith Haring, registrado en la lista de Patrimonio de Victoria en 2004 (Smith 2016); o en Inglaterra, con la obra de Banksy Spybooth, que en 2015, tras diversos movimientos sociales de la comunidad de Cheltenham y ante el temor a que el dueño del muro vendiera la obra, fue incluida en el registro de bienes patrimoniales de la ciudad, sin poder impedir por ello que finalmente la obra desapareciera (Hansen 2018).

Por consiguiente, el foco de atención no está tanto en relación con si se considera o no patrimonio cultural, sino al hecho de si estas obras, efímeras, bien por su naturaleza, bien por la del contexto en el que se desarrollan, deben de ser atendidas de un modo diferente, en previsión de que la documentación que dejemos para futuras generaciones sea lo menos sesgada posible y también tomando en consideración que alguna de ellas pueda querer ser conservada en su materialidad física, acercando su realidad a la idea de "monumento".

La documentación total del fenómeno es una utopía, y la documentación parcial tendrá siempre el sesgo de quien hace la selección de las obras que se han de documentar. Dada la creciente vertiente digital desarrollada por los propios artistas, que encuentran en el espacio virtual un nuevo lugar común en el que interactuar con el público (Coluccio 2019) quizá los esfuerzos pudieran orientarse en encontrar el modo de interrelacionar la información que ya generan los propios artistas de un modo eficaz y sostenible.

Parece evidente que grafiti y arte urbano son testigos innegables de una sociedad concreta en una época determinada: la nuestra, por cierto, globalizada, como el mismo fenómeno en sí. Son, como lo fueron otras culturas y subculturas, reflejo de las características que nos definen y por tanto de nuestras costumbres, hábitos y valores. 


\section{NOTAS}

1. Street art en Melbourne (Australia): https://www.melbourne.vic.gov.au/arts-and-culture/art-outdoors/pages/ street-art.aspx [Consulta: 16/04/2021].

2. Grupo de Arte Urbano y Público del GE-IIC: https:// www.ge-iic.com/arte-urbano/ [Consulta: 16/04/2021].

3. CAPuS Project: http://www.capusproject.eu [Consulta: 16/04/2021].

\section{BIBLIOGRAFÍA}

- Barrak, A. (2019) Cuando el arte invade la calle. Correo de la UNESCO, un solo mundo voces múltiples. Disponible en: https://es.unesco.org/courier/2019-2/cuando-arte-invade-calle [Consulta: 06/04/2021]

- Brajer, I. (2015) Values and the preservation of contemporary outdoor murals. En: Sánchez, M., Shark, W. y Fuster, L. (ed.) Conservation issues in modern and contemporary murals. Londres: Cambridge Scholars Publishers, pp. 40-58

- Coluccio, C.E. (2019) "Viral Mural", entre el muralismo y los espacios virtuales. Ge-conservacion, n. ${ }^{0} 16$, pp. 145153. Disponible en: https://doi.org/10.37558/gec.v16i0.703 [Consulta: 06/04/2021]

- Hansen, S. (2018) Heritage protection for street art? The case od Banksy's Spybooth. Nuart Journal, vol. 1, n. ${ }^{\circ}$ 1, pp. 31-35

- Luque. L. y Moral, C. (2021) El arte urbano como patrimonio inmaterial. Posibilidades para su protección y difusión. En: I Simposio anual de Patrimonio Natural y Cultural ICOMOS España. Valencia: Universitat Politècnica de València, pp. 57-64. Disponible en: http://ocs.editorial.upv.es/index.php/ icomos_es/icomos2019/paper/viewFile/12513/5855 [Consulta: 06/04/2021]

- Merrill, S. (2015) Keeping it real? Subcultural graffiti, street art, heritage and authenticity. International Journal of Heritage Studies, vol. 21, n. ${ }^{\circ} 4$, pp. 369-389, https://doi.org/10.1080/135 27258.2014.934902 [Consulta: 06/04/2021]

- Nogueira, A. (2014) Emerging issues of Street Art valuation as Cultural Heritage. En: Lisbon Street-Art \& Urban CreativityInternational Conference. Lisbon: Urbancreatvity.org, pp. 21-27

- Smith, C. (2016) Community Rights to Public Art. St John's Law Review, n. ${ }^{\circ}$ 90, pp. 369-413 